\title{
How Does the Market Interpret Analysts' Long-term Growth Forecasts?
}

\author{
Steven A. Sharpe \\ Division of Research and Statistics \\ Federal Reserve Board \\ Washington, D.C. 20551 \\ (202)452-2875 \\ ssharpe@frb.gov
}

April, 2004

Forthcoming in the Journal of Accounting, Auditing and Finance. The views expressed herein are those of the author and do not necessarily reflect the views of the Board nor the staff of the Federal Reserve System. I am grateful for comments and suggestions from Jason Cummins, Steve Oliner, and an anonymous referee, and members of the Capital Markets Section at the Board. Excellent research assistance was provided by Eric Richards and Dimitri Paliouras. 


\title{
How Does the Market Interpret Analysts' Long-term Growth Forecasts?
}

\begin{abstract}
The long-term growth forecasts of equity analysts do not have well-defined horizons, an ambiguity of substantial import for many applications. I propose an empirical valuation model, derived from the Campbell-Shiller dividend-price ratio model, in which the forecast horizon used by the "market" can be deduced from linear regressions. Specifically, in this model, the horizon can be inferred from the elasticity of the price-earnings ratio with respect to the longterm growth forecast. The model is estimated on industry- and sector-level portfolios of S\&P 500 firms over 1983-2001. The estimated coefficients on consensus long-term growth forecasts suggest that the market applies these forecasts to an average horizon somewhere in the range of five to ten years.
\end{abstract}




\section{Introduction}

Long-term earnings growth forecasts by equity analysts have garnered increasing attention over the last several years, both in academic and practitioner circles. For instance, one of the more popular valuation yardsticks employed by investment professionals of late is the ratio of a company's PE to its expected growth rate, where the latter is conventionally measured using analysts' long-term earnings growth forecasts. An expanding body of academic research uses equity analysts' earnings forecasts as well.

One of the more common and important applications is the measurement of the equity risk premium; and, as Chan, Karceski and Lakonishok (2003) argue, analysts' long-term forecasts are a "vital component" of such exercises. However, inferences from such studies can be quite sensitive to how those long-term growth forecasts are applied. Unfortunately, as evidenced by the range of assumptions employed in these applications, how these forecasts should be interpreted - that is, the horizon to which they ought to be applied - is quite ambiguous. For instance, Claus and Thomas (2001), in gauging the level of the equity risk premium, apply these growth forecasts to years 3 through 5; and beyond year 5 they apply a fixed growth rate assumption. At the other extreme, Harris and Marston (1992, 2001) and Khorana, Moyer and Patel (1999), apply these growth forecasts to an infinite horizon. In other studies, the assumed horizon usually falls somewhere in the middle. ${ }^{1}$

The implications are not purely academic, as these growth forecasts, or the perceptions they reflect, appear to have been a key factor driving equity market valuations skyward during the latter half of the 1990s. Indeed, as shown in figure 1, the PE ratio for S\&P500, the ratio of the index price to 12-month-ahead operating earnings, rose more than 50 percent between January 1994 and January 2000. Over roughly that same time period, the "bottom-up" (weighted average) long-term earnings growth forecast for the S\&P500 climbed almost 4 percentage points to nearly 15 percent, well above previous peaks. Findings in Sharpe (2001) suggest this was no

\footnotetext{
${ }^{1}$ To estimate the intrinsic value of the companies in the Dow Jones Industrials Index, Lee, Myers and Swaminathan (1999) use the long-term earnings grow th rate as a proxy for expected growth only through year 3. They implicitly pin down earnings growth beyond that point by assuming that the rate of return on equity reverts toward the industry median over time. Gebhardt, Lee and Swaminathan (2001) also use this formulation.
} 
coincidence, that Wall Street's long-term growth forecasts have been a significant factor in valuations; however, because of their relatively short history and high autocorrelation, the size of that influence is difficult to gauge in aggregate analysis.

\section{(Insert Figure 1)}

In this study, I attempt to gauge the appropriate horizon over which to apply these growth forecasts by appealing to the market's judgement, that is, by inferring the horizon from market prices. In particular, I propose a straightforward empirical valuation model in which linear regression can be used to deduce the forecast horizon that the "market" uses to value stocks. This model is a descendent of the Campbell and Shiller $(1988,1989)$ dividend-price ratio model, which is an approximation to the standard dividend-discount formula. As in Sharpe (2001), their model is modified in order to emphasize the expected dynamics of earnings rather than

dividends. In the resulting framework, the horizon over which the market applies analysts' longterm growth forecasts can be inferred from the elasticity of the PE ratio with respect to the growth forecast.

I estimate the model using industry- and sector-level portfolios of S\&P 500 firms, constructed from quarterly data on stock prices and consensus firm-level earnings forecasts over 1983-2001. The estimated coefficients on consensus long-term growth forecasts suggest that the market applies these forecasts to an average horizon somewhere in the range of 5 to 10 years. Thus, these growth forecasts are more important for valuation than assumed in the many applications that treat them as 3-to-5 year forecasts, though far less influential than forecasts of growth into perpetuity. Among other implications, the results suggest that the increase in S\&P500 constituent growth forecasts during the second half of the 1990s can explain up to half of the concomitant rise in their PE ratios.

\section{The Relation Between PE Ratios, Expected EPS Growth, and Payout Rates}

\subsection{The Basic Idea}

The principal modeling goal is to develop a simple estimable model of the relationship between the price-earnings ratio and expected earnings growth. As discussed in the subsequent section, by expanding out terms in the model of Campbell and Shiller (1988), we can produce the following relation for any equity or portfolio of equities: 


$$
\log \frac{P_{t}}{E P S_{t+1}} \approx \sum_{j=2}^{\infty} \rho^{j-1} g_{t+j}+Z_{t}
$$

where $P_{t}$ is the current stock price, EPS $S_{t+1}$ is expected earnings per share in the year ahead, $g_{t+j}$ is expected growth in earnings per share in year $\mathrm{t}+\mathrm{j} . \rho$ is a constant slightly less than 1 , similar to a discount factor, and $Z_{t}$ is a function of the expected dividend payout rates and the required return.

For the analysis that follows, divide the discounted sum of expected EPS growth rates into two pieces:

$$
\sum_{j=2}^{\infty} \rho^{j-1} g_{t+j}=\sum_{j=2}^{T} \rho^{j^{-1}} g_{t}^{L}+\sum_{j=T+1}^{\infty} \rho^{j-1} g^{\infty}
$$

where $g_{t}^{L}$ represents the expected average EPS growth rate over the next T years, measured by analysts' long-term growth forecasts, and $\mathrm{g}^{\infty}$ is the average growth rate expected thereafter. This amounts to assuming there is a finite horizon, T, over which investors formulate their forecasts of earnings growth; beyond that horizon, expected average growth $\left(\mathrm{g}^{\infty}\right)$ is assumed constant or, at a minimum, uncorrelated with $g^{L}$.

We thus rewrite (1) as follows:

$$
\log \frac{P_{t}}{E P S_{t+1}}=\frac{\rho\left(1-\rho^{T-1}\right)}{1-\rho} g_{t}^{L}+Z_{0 t}(T)
$$

where $\frac{\rho\left(1-\rho^{T-1}\right)}{1-\rho}=\left[\rho+\rho^{2}+\rho^{3}+\ldots+\rho^{T-1}\right]$ and $Z(T)$ now subsumes an additional (independent) term containing the growth rate expected after T. Clearly, the longer the horizon over which investors' formulate "long-term" growth forecasts, the larger will be the "effect" on stock prices of any change in that expected (average) growth rate. For instance, suppose $\rho=0.96$; if investors apply the forecast on a horizon running between year 1 through year 5 (growth in year 2, 3, 4, and 5) the multiplier on $g^{L}$ is 3.6. If, instead, this horizon ran from year 1 through year 10 , the multiplier would be 7.4. The main contribution of this paper is to infer this horizon by estimating this multiplier--the elasticity of the PE ratio with respect to the expected growth rate-in the context of the valuation model described more thoroughly below. 


\subsection{Derivation of the Empirical Model}

Campbell and Shiller (1988) show that the log of the dividend-price ratio of a stock can be expressed as a linear function of forecasted one-period rates of return and forecasted oneperiod dividend growth rates; that is,

$$
\log \frac{D_{t}}{P_{t}}=E_{t}\left[\sum_{j=1}^{\infty} \rho^{j-1} r_{t+j}-\sum_{j=1}^{\infty} \rho^{j-1} \Delta d_{t+j}\right]+k
$$

where $D_{\mathrm{t}}$ is dividends per share in the period ending at time $\mathrm{t}$ and $P_{t}$ is the price of the stock at $\mathrm{t}$. On the right hand side, $E_{t}$ denotes investor expectations taken at time t, $r_{t+j}$ is the return during period $t+j$, and $\Delta d_{t+j}$ is dividend growth in $t+j$, calculated as the change in the log of dividends. The $\rho$ is a constant less than unity, and can be thought of as a pseudo-discount factor.

Campbell-Shiller show that $\rho$ is best approximated by the average value over the sample period of the ratio of the share price to the sum of the share price and the per share dividend, or $\mathrm{P}_{\mathrm{t}} /\left(\mathrm{P}_{\mathrm{t}}+\mathrm{D}_{\mathrm{t}}\right) . k$ is a constant that ensures the approximation holds exactly in the steady-state growth case. In that special case, where the expected rate of return and the dividend growth rate are constant, equation (4) collapses to the Gordon growth model: $D_{t} / P_{t}=R-G$.

The Campbell-Shiller dynamic growth model is convenient because it faciliates the use of linear regression for testing hypotheses. As pointed out by Nelson (1999), the Campbell Shiller dividend-price ratio model can be reformulated by breaking the log dividends per share term into the sum of two terms--the log of the earnings per share and the log of the dividend payout rate. When this is done and terms are rearranged, then the Campbell-Shiller formulation can be rewritten as:

$$
\log \frac{E P S_{t}}{P_{t}}=E_{t}\left[\sum_{j=1}^{\infty} \rho^{j^{-1}} r_{t+j}-\sum_{j=1}^{\infty} \rho^{j^{-1}} g_{t+j}-(1-\rho) \sum_{j=1}^{\infty} \rho^{j^{-1}} \phi_{t+j}\right]+k
$$

where $E P S_{t}$ represents earnings per share in the period ending at $t, \mathrm{~g}_{\mathrm{t}+\mathrm{j}}=\Delta \log \mathrm{EPS}_{\mathrm{t}+\mathrm{j}}$, or earnings per share growth in $t+j$, and $\phi_{\mathrm{t}+\mathrm{j}}=\log \left(\mathrm{D}_{\mathrm{t}+\mathrm{j}} / \mathrm{EPS}_{\mathrm{t}+\mathrm{j}}\right)$, the $\log$ of the dividend payout rate in $t+j$.

This reformulation is particularly convenient as it facilitates a focus on earnings growth. 
To simplify and further focus data requirements on earnings forecasts (as opposed to dividend forecasts), I assume that the expected path of the payout ratio can be characterized by a simple dynamic process. In particular, reflecting the historical tendency of payout ratios to revert back toward their target levels subsequent to significant departures, I assume that investors forecast the (log) dividend payout ratio as a stationary first-order autoregressive process:

$$
E_{t} \phi_{t+j}=\lambda \phi^{*}+(1-\lambda) \phi_{t+j-1}
$$

In words, the payout rate is expected to adjust toward some norm, $\phi^{*}$, at some speed $\lambda<1$.

It is straightforward to show that, given (6), the discounted sum of expected log payout ratios in (5) can be written as a linear function of the current payout rate:

$$
E_{t} \sum_{j=1}^{\infty} \rho^{j^{-1}} \phi_{t^{+j}}=\frac{1-\lambda}{1-\rho(1-\lambda)} \phi_{t}+\frac{\lambda /(1-\rho)}{1-\rho(1-\lambda)} \phi^{*}
$$

The final equation is arrived at by substituting into (5) the assumed structure of expected payout rates (7), and the assumed structure of earnings growth forecasts (2). Rearranging terms, and defining $\mathrm{R}_{\mathrm{t}}$ as the discounted sum of expected returns:

$$
\log \frac{P_{t}}{E P S_{t+1}}=\frac{\rho\left(1-\rho^{T-1}\right)}{1-\rho} g_{t}^{L}+\alpha \phi_{t}+\left[\frac{\rho^{T+1}}{1-\rho} g^{\infty}+(1-\alpha) \phi^{*}\right]-R_{t}+k
$$

where $\alpha \equiv \frac{(1-\rho)(1-\lambda)}{1-\rho(1-\lambda)}$ is between 0 and 1 .

\subsection{Empirical Implementation}

To translate equation (8) into a regression equation with the log PE ratio as dependent variable, note that the first pair of right-hand side variables--the long-term growth forecast $\left(g^{L}\right)$ and the current log dividend payout rate $(\phi)$--are observable, at least by proxy. The pair of terms in brackets are the expected "long-run" log payout ratio and expected earnings growth in the "out years," both of which are unobservable and assumed constant; thus, they are absorbed into the regression constant. Even if constant over time, they are likely to vary cross-sectionally, 
which suggests the need for additional controls or industry dummies. Finally, expected future returns, $\mathrm{R}_{\mathrm{t}}$, are also unobservable. To control for time variation in expected returns, macroeconomic factors are added to the list of regressors. As discussed below, cross-sectional variation in expected returns is dealt with by including fixed effects.

Letting $i$ represent a firm or portfolio of firms, and letting $\mathrm{Z}$ represent proxies for, or factors in, expected returns, $(8)$ is translated into the following regression equation:

$$
\log \frac{P_{i t}}{E P S_{i, t+1}}=\beta g_{i t}^{L}+\alpha \phi_{i t}+\beta_{0 i}-\gamma Z_{i t}+u_{i t}
$$

with $u_{i t}$ a mean-zero error term, assumed to be uncorrelated with the explanatory variables.

Given an assumed value for $\rho$, the horizon over which investors apply analysts' longterm growth forecasts can be inferred from the magnitude of $\beta$, which should be positive. For these calculations I assume $\rho=0.96$; in that case, if long-term growth horizon applied to the five years of growth beginning at the end of the current year ( $T=6$ ), we would expect the coefficient on long-term growth to be 4.4 . The resultant mapping from horizon $\mathrm{T}$ to implied coefficient is provided in the following table:

\begin{tabular}{|c|c|c|c|c|c|c|c|c|c|}
\hline $\mathrm{T}$ & 2 & 3 & 4 & 5 & 6 & 8 & 10 & 20 & $\infty$ \\
\hline$\beta$ & 0.96 & 1.9 & 2.8 & 3.6 & 4.4 & 6.0 & 7.4 & 12.9 & 24 \\
\hline
\end{tabular}

To understand why the best approximation for $\rho$ is $\frac{P}{P+D}$, consider the case where $g$ is the expected growth into perpetuity $(\mathrm{T}=\infty)$. In this case, the coefficient on $g$, according to (8), would boil down to simply $\rho /(1-\rho)=P / D$. But this is precisely the implied effect of growth on price in the Gordon (constant) growth model; in that model, $\frac{\partial \log P}{\partial g}=\frac{1}{r-g}=\frac{P}{D}$. Moreover, as long as the horizon is not extremely distant -- the coefficient on $\mathrm{g}^{\mathrm{L}}$ is not too large -- then the inferred horizon is not very sensitive to the precise choice of $\rho .^{2}$

According to the model (8), the coefficient on the dividend payout rate should lie between 0 and 1 . It would equal 1 if the current payout rate was expected to be maintained

\footnotetext{
${ }^{2}$ For instance, if $T=6$, then the coefficient $(\beta)$ is predicted to be 4.3 for $\rho=0.95$ versus 4.6 for $\rho=0.97$.
} 
forever $(\lambda=0)$; in most cases it should be much closer to zero than 1 , even if the dividend payout rate is expected to revert quite slowly back to the long-run payout rate. For instance, if $\lambda=0.1$ (the payout rate is adjusted annually by 10 percent of the gap between the desired and current level), then the theoretical coefficient on the payout rate (given $\rho=.96$ ) would be 0.27 .

Clearly, the assumed dynamics of the payout rate are a simplification. It is quite plausible, for instance, that the long-run target for any given industry evolves over time. If that were the case, then we would expect the current payout rate to carry more information about the average future payout; thus, its coefficient would be larger than that what is implied by short-run autocorrelations, and we would interpret it somewhat differently. However, this would not alter our interpretation of the coefficient on the growth forecast. Indeed, excluding the payout rate from the regression or adding another lag does not substantially alter inferences drawn with regard to the growth horizon.

As in much of the research on expected returns, estimation is conducted on portfolios of firms. One potential benefit of this aggregation is a reduction in potential measurement error that comes from using analysts' forecasts as proxies for long-term growth forecasts. But using portfolios is also necessary because model (8) cannot be applied literally to firms that do not have positive dividends and earnings because the log payout ratio would be undefined. The model is too stylized for application to very immature firms. To some extent, this observation guides the choice of portfolio groupings. In particular, firms are grouped into portfolios by industry, rather than by characteristics that would be correlated with firm size or maturity.

\section{Data and Sample Description}

\subsection{The data}

The sample is constructed using monthly survey data on equity analyst earnings forecasts and historical annual operating earnings, both obtained from I/B/E/S International. A dataset of quarterly stock prices and earnings forecasts is constructed using the observations from the middle month of each quarter (February, May, August, and November), beginning in 1983, when long-term growth forecasts first become widely available in the $\mathrm{I} / \mathrm{B} / \mathrm{E} / \mathrm{S}$ database. The sample in each quarter is built using firms belonging to the S\&P500 at the time. Sample firms must also have consensus forecasts for earnings per share in the current fiscal year (EPS1) and the 
following fiscal year (EPS2), as well as a consensus long-term growth forecast. Data on dividends per share are mostly drawn from the historical I/B/E/S tape, though missing values in the early part of the sample are filled in using Compustat.

The data of greatest interest in this study are the equity analysts' long-term growth forecasts, which I measure using the median analyst forecast from I/B/E/S, where the typical forecast represents the "expected annual increase in operating earnings over the company's next full business cycle." In general, these forecasts refer to a period of between three to five years (I/B/E/S International, 1999). Clearly, this description is fairly ambiguous about the horizon of these forecasts, though three to five years is probably the most widely cited horizon.

The measure of expected earnings used for the denominator of the PE ratio is constructed using forecasts for both current-year and next-year earnings. For any given observation, a firm's "12-month-ahead" earnings per share $E P S_{t}=w_{m} * E P S 1+\left(1-w_{m}\right) * E P S 2$, where the weight $\left(w_{\mathrm{m}}\right)$ on current year EPS is proportional to the fraction of the current year that remains. For instance, $w_{m}$ is 1 if the firm just reported its previous fiscal-year earnings within the past month, and it equals $11 / 12$ if the firm reported its previous year's earnings one month ago. The PE ratio is then calculated as the ratio of current price to 12-month-ahead earnings.

To construct the lagged dividend payout ratio, I create an analogous measure of 12month lagging earnings. Specifically; 12-month lagging earnings, or $E P S_{t-1}=w_{m}{ }^{*} E P S O+(1-$ $\left.w_{m}\right) * E P S 1$, where EPSO is earnings per share reported for the previous fiscal year. The dividend payout rate is then calculated as the ratio of the firm's most recent (annualized) dividend per share to its 12-month lagging operating earnings per share. Prior to 1985 , the dividend variable is not provided in the $\mathrm{I} / \mathrm{B} / \mathrm{E} / \mathrm{S}$ data. For these observations, the dividend per share value is taken from Compustat.

\subsection{Construction of Sector and Industry Portfolios}

For each quarterly observation, firms are grouped into portfolios using two alternative levels of aggregation. In the more aggregated case, firms are grouped into 11 sectors, which are broad economic groupings as defined by I/B/E/S (Consumer Services, Technology, ...etc.). The second portfolio grouping is comprised of industry-level portfolios, constructed using $\mathrm{I} / \mathrm{B} / \mathrm{E} / \mathrm{S}$ industry codes that are similar in detail to the old 2-digit Standard Industrial Classification (SIC) 
industry groupings. For instance, the technology sector is broken down into (i) computer manufacturers, (ii) semiconductors and components, (iii) software and EDP services, and (iv) office and communication equipment.

Each quarterly observation for each variable is constructed by aggregating over all portfolio members in that quarter--S\&P500 firms in the given sector (or industry). Constructing a portfolio aggregate long-term growth forecast is somewhat tricky because these variables are growth rates and because there is no clearly optimal set of weights for aggregating these growth rates. The most intuitive choice would be the level of a firm's previous-year earnings; but this would be nonsensical in the case where some firms had negative earnings. To get around this, I use a measure of expected earnings; in particular, each firm's weight is calculated as current shares times the maximum of [EPS1, EPS2, 0]. Because EPS2 is almost always positive for S\&P500 firms, this approach avoids the problem of potentially negative weights and minimizes the number of companies that get zero weight.

The dependent variable, the price-earnings ratio, is constructed by summing up the market values of all (S\&P500) sector or industry members, and then dividing by the sum of their expected 12-month ahead earnings. Similarly, dividend payout rates at the portfolio level are constructed by summing the dividends (dividends per share times shares outstanding) of portfolio members and dividing by the sum of their 12-month lagging earnings.

The payout rate and the PE ratio are undefined when their denominators are negative; thus, these variables are occasionally undefined when we use the finer industry-level portfolio partition. Moreover, there is a higher frequency of negative observations on 12-month lagging earnings than on 12-month ahead earnings (presumably owing to analysts' optimistic bias); that is, actual earnings are negative more often than expected earnings. To reduce the loss of industry-level observations as a result of negative earnings, in constructing industry payout ratios, I substituted an industry's 12-month ahead earnings for its 12-month lagging earnings in cases where the latter is negative and the former is not, with little effect on the results.

\subsection{Controls for expected returns}

Because empirical inferences are partly drawn from the time series dimension of the data, I include a couple proxies for the expected long-run return on the market portfolio, specifically 
the long-term (10-year) government bond yield and the risk spread on corporate bonds, equal to the difference between the yields on the Moody's Aaa and Baa corporate bond indexes. In light of the findings by Fama and French (1989) and others, that excess expected equity returns are positively related to the risk spreads on bonds, we expect the PE ratio to be negatively related to both the corporate risk spread and the bond yield.

A third macro factor I consider is the expected inflation rate, as proxied by the fourquarter expected inflation rate from the Philadelphia Federal Reserve survey of professional forecasters. As suggested in Sharpe (2001), expected inflation also appears to be a positive factor in required equity returns (before taxes), perhaps because inflation raises the effective tax rate on real equity returns.

I do not construct a measure of the industry or sector portfolio betas, or any other crosssectional determinants of expected returns. First, the bulk of empirical research weighs in on the side of finding very little role for beta. Perhaps most salient study in this regard is Gebhardt, Lee, and Swaminathan (2001), which also analyzes expected returns with an earnings-based ex ante measure. They find beta to be of little value in explaining cross-sectional differences in expected return. On the other hand, their findings suggest that industry membership is a factor in expected returns; I control for potential industry factors in expected returns by including fixed industry effects. ${ }^{3}$

\subsection{Sample Statistics}

After dropping the first observation per sector or industry in order to create one lag on the PE ratio, the sample runs from 1983:Q2 to 2001:Q2. This leaves a potential of 73 quarterly

\footnotetext{
${ }^{3}$ Indeed, Gebhardt, et. al find the long-term growth forecast to be a positive factor in firm-level expected returns. But that finding might be the result of assumptions they use to construct their ex ante measure of expected return. If their measure builds in too long a horizon on the growth forecast, then the growth forecast will appear to have a positive effect on expected return (or a negative effect on valuations). In their "terminal value" calculation, the slow decay rate of ROE, and the use of median industry ROE as the expected ROE for perpetuity, may implicitly build in too long a horizon on current expected earnings growth or, more precisely, on the value of ROE in year $t+4$. Indeed, it is somewhat curious that long-term growth is a significant factor in expected return only when the regression also includes the book-to-market ratio-another key component in the construction of the dependent variable.
} 
observations for each of 11 sectors, or 803 sector-time observations. In addition to excluding observations for which earnings are negative or dividends are zero, those with extreme values are also filtered out. In particular, observations are excluded if either the portfolio PE ratio exceeds 300 or its dividend payout rate exceeds 5.0.

In the case of sector portfolios, these filters remove only 2 observations; and no observations are lost as a result of negative earnings or zero dividends. Distributions of the key variables for the sector portfolios are depicted by the top number among each pair of numbers in table 1. The average sector price-earnings ratio over the sample period is about 14 , and it ranges from 3.5 to 54.1. The average dividend payout rate is 0.45 (or 45 percent of earnings), with a range of 0.08 to 2.16 . The average expected long-term growth rate is 11 percent, with a range of 5 to 20 percent.

Correlations among variables are shown in the bottom half of the table. The PE ratio is strongly correlated with the earnings growth forecast, as theory would suggest, but it is uncorrelated with the dividend payout rate. The earnings growth forecast is negatively correlated with the dividend payout rate, consistent with the prediction that firms with lower growth prospects pay out a higher proportion of their dividends.

In the case of industry portfolios, roughly 120 observations are excluded where industry dividends are zero or, in a handful of cases, where expected year-ahead earnings are negative, leaving 4071 observations on 66 industries. ${ }^{4}$ Another 14 observations are excluded because the PE ratio exceeds 300 or the dividend payout rate exceeds 5, leaving 4057 industry-quarter observations, an average of about 62 quarters per industry. Distributions and correlations for the industry portfolio variables are depicted by the bottom figures among the pairs in table 1 .

\section{Empirical Results}

\subsection{Sector Regressions}

Table 2 shows the results of sector portfolio regressions with the log of the PE ratio as dependent variable. Heteroskedasticity and autocorrelation-consistent (Newey-West) standard

\footnotetext{
${ }^{4}$ I have also excluded 5 very small industries for which the average total industry market value (over the sample period) is less than $\$ 1$ billion. Also note that not all industries exist over the entire sample.
} 
errors are reported below the coefficient estimates. Column (1) shows the simplest specification; it includes the earnings growth forecast, the sector payout rate, the yield on the 10-year Treasury bond, and the risk spread on corporate bonds. The coefficient estimate on the growth forecast is 8.05 , with a standard error of 0.5 , indicating relatively high precision. The magnitude of the coefficient suggests that growth forecasts reflect expectations over a fairly long horizon. In particular, given that $\frac{\rho\left(1-\rho^{T-1}\right)}{1-\rho}$ equals 7.75 for $\mathrm{T}=10$ and 8.5 for $\mathrm{T}=11$, the inference would be that the long-term growth forecast represents the expected growth rate for a 9 or 10 year period, starting from the coming year's expected level of earnings.

The coefficient on the payout rate, 0.34 , falls within the $[0,1]$ range dictated by theory; but, interpreted literally, the magnitude of the coefficient implies that payout rates adjust very slowly toward their long-run desired levels. Interpreted more loosely, one could infer that the current payout rate conveys some information about a sector's long-run desired payout rate, which is not likely to be constant over the very long run as assumed by the model.

The coefficients on the bond yield and the risk spread are both negative, as theory and previous empirical results would predict. The coefficient on the Treasury bond yield implies that a one percentage point increase in long-term yields drives down the PE ratio by about 12 percent -- or, holding E constant, drives down the stock price 12 percent. The regression R-squared is quite high, suggesting these four variables explain about 70 percent of the overall cross-sectional and time series variation in price-earnings ratios. The root mean squared error is 0.2 .

One problem with this specification, however, is the presence of strong autocorrelation in the errors, reflected in a Durbin-Watson statistic of 0.32. In specification (2), this is rectified by modeling the dynamics with the addition of a lagged dependent variable, the lagged PE ratio, which receives a coefficient of 0.75 . Not surprisingly, adding this regressor boosts the Rsquared substantially, to 0.910 , and cuts the root mean squared error in half. The Durbin-h test now strongly rejects the presence of autocorrelation.

Interpreting the coefficient on the growth forecast is a bit more complicated here because that coefficient, equal to 2.00, now represents only the "impact effect". The total long-run effect of a change in the growth forecast is equal to the impact coefficient divided by one minus the coefficient on the lagged PE, or $2 /(1-0.75)=8$. Thus, the conclusion from the original regression holds up: the growth forecast still appears to represent a horizon of about 9 years. 
The long-run effect of the payout rate is 0.28 , only a bit smaller than the static estimate. One notable difference from the static model is that the sign on the risk spread flips to positive, although that variable is no longer statistically significant. Thus, once we account for growth expectations and the underlying dynamics, the risk spread no longer has marginal explanatory power for stock valuations.

The third and fourth specifications address the potential omitted variable problem. Gebhardt, et. al (2001) find sector-level factors in expected returns. If sector-level (but nongrowth-related) factors are correlated with sector long-term growth expectations, then the coefficient on growth forecasts will be biased. Sector-level expected-return factors can be removed using a fixed effects estimator. In column (3), results are shown for the static version of the model estimated on sector-mean-adjusted variables; and, in (4), results are shown when fixed effects are similarly incorporated into the dynamic model. In both cases, the results continue to yield conclusions similar to the first specification. ${ }^{5}$

Finally, I consider the possibility that omitted macroeconomic factors in expected returns are correlated with changes in the average sector growth forecast over time. Column (5) shows the results from adding expected inflation, specifically, expected inflation over the next four quarters as measured by the Philadelphia Fed survey of professional forecasters. As shown by Sharpe (2001), expected inflation seems to be related to both expected earnings growth and expected returns. In addition, controlling for expected inflation allows us to interpret the estimated effect of changes in expected long-term growth as reflecting changes in real growth expectations. In any case, adding expected inflation to the dynamic specification reduces somewhat the estimated effect of expected growth. Here, the long-run effect of 6.63 is consistent with a horizon between 7 and 8 years.

The final specification takes a more agnostic approach to macro factors and adds year dummies (in addition to the fixed sector effects). This eliminates any effect of the growth forecast that might be purely time-driven, and thus provides the most conservative estimate of the effect of these earnings expectations. Indeed, the long-run coefficient on the growth forecast falls to 5.45 in this regression, which suggests a horizon of about 6 years. Considering the

\footnotetext{
${ }^{5}$ Given the sample size, the small sample bias that arises when a lagged dependent variable is used in conjunction with fixed effects should not be an issue.
} 
totality of the findings in table 2 , one would conclude that the horizon of the earnings growth forecast falls somewhere in the range of 6 to 10 years.

\subsection{Industry Regressions}

An analogous set of results based on narrower industry-level portfolios is shown in table

3. The industry-level results generally follow the pattern of the sector-portfolio results, with one important difference. In these regressions, the long-run coefficient on the growth forecast tends to be about two-thirds the magnitude found in the analogous sector-level regressions. In particular, the coefficient estimate on the growth forecast runs from 5.4 in the specifications without fixed effects down to 3.9 in the specification with both fixed industry and time effects. These results would suggest that investors apply the growth forecast to a somewhat shorter horizon - between 5 and 7 years, compared to the 6 to 10 -year range suggested by the sectorlevel analysis.

One potential explanation of the difference between the sector- and industry-level coefficient estimates revolves around the idea that the analyst growth forecasts measure investor expectations with error. Assuming minimal measurement error on other regressors, then measurement error in the growth forecast would produce a downward bias in the coefficient on expected growth. Furthermore, if measurement errors were not highly correlated across firms or industries within a given sector, then using a higher level of aggregation would tend to reduce this measurement error. A similar but more structural explanation for the difference in results could be that investor expectations of a firm's or industry's growth beyond the very near term is partly reflected in growth expectations for other firms or industries within the same sector. Under either interpretation, we would expect sector growth forecasts to help explain variation in industry PE ratios, even after controlling for the industry growth forecast.

This hypothesis can be examined by reestimating the industry regressions but with the sector growth forecast as an additional explanatory variable. With both the industry and sector growth forecasts in the regression, the sum of their two coefficients can be interpreted as measuring the total effect of an increase in forecasted industry growth that is matched by an equal-sized increase in the forecast for sector-level growth.

The key results from re-estimating specification (1) are provided in the first column of 
Table 4. As shown, the coefficients on the industry and sector growth forecasts are 4.35 and 1.87 , respectively. These two coefficients sum up to 6.22 , which is larger than the original industry growth effect from the analogous industry-level regression (table 3 ) though still smaller than the coefficient in the sector-level regression (table 2). Results from rerunning specification (4) are shown in the second column. The estimated (long-run) coefficients on industry and sector growth forecasts are 3.62 and 3.41, respectively. Thus, it again appears that sector growth expectations help explain industry valuations. Here, the coefficients sum to a total effect of 7.03, which is closer to the long-run coefficient on growth in the sector regression (7.92) than to that in the industry regression $(4.53){ }^{6}$

\subsection{Robustness over time}

As a final robustness test of the model and its application to the analyst forecast data, I split the data into early (1983-1991) and late (1992-2001) subsamples and reestimate some of the key industry- and sector-level regressions. This experiment provides evidence on the extent to which our inferences depend upon the time period under consideration. Table 5 compares the coefficients estimates on the long-term growth forecast for the two time periods, under four alternative specifications (regressions (1) and (4) for both the sector and industry portfolios). Although not shown in the table, the coefficient on the dividend payout rate is always positive and less than 0.5 , while the coefficient on the Treasury bond yield is always negative.

In short, the results do indicate that there is a substantial difference between the early and late sample valuation effects of long-term growth forecasts. Although statistically positive in all cases, the coefficient on the growth forecast is about double in the later subsample compared to the analogous early-sample estimate. For instance, in the simple sector regression (1), the earlysample coefficient on growth is 6.1, whereas the late sample coefficient in 10.0. This suggests that the horizon in the early sample is about 7 years, whereas it is closer to 12 years in the more recent period. At the other end of the spectrum, the dynamic fixed-effect regression (4) on

\footnotetext{
${ }^{6}$ An alternative tack, which amounts to the same test, would be to put the industry growth forecast and, second, the differential between the sector and industry growth forecasts in the regression. In this case, the coefficient on the industry growth forecast would be 7.02, and the coefficient on the differential would be 3.4 .
} 
industry portfolios produces a long-run coefficient of 2.3 in the early period, suggesting a 2 to 3 year horizon, versus 4.5 in the late period, consistent with a 5 -year horizon. ${ }^{7}$ We are thus led to the inference that long-term growth forecasts carried more weight, or were applied to a longer horizon, during the past decade. This could owe either to the fact that analyst forecasts have become more widely applied in valuation analysis or to an increased emphasis placed on these long-term growth forecasts by analysts and their customers.

\subsection{Caveats}

Before concluding, some cautionary remarks are in order. It should be emphasized that the interpretation 0 of the results is conditioned upon the maintained hypothesis that the assumptions behind the model are a reasonably approximation of reality. While this is true of any econometric application, it is important here because the conclusions revolve around the magnitude of the key coefficients, rather than just their sign and statistical significance. Clearly, there are a number of rationales one could invoke for why that model might be prone to either overestimate or underestimate the forecast horizons imputed to investors.

On one hand, the analysis ignores the potential influence of momentum, or positivefeedback, trading, which would cause stock prices to overreact to fundamentals. In other words, if stock prices in an industry rise due to an increase in the growth outlook over the next few years, momentum trading could amplify the ultimate stock price effect. In that case, the model would overstate the duration that investors actually attribute to growth forecasts.

On the other and, it is possible that the required return on a firm or industry's stock is positively related to its expected growth rate, since high growth firms or industries may be riskier. This would imply the presence of a second (negative) channel through which growth expectations might influence $\mathrm{PE}$ ratios, making identification problematic. If we fail to control for a any such negative effect on stock prices coming through a required-return channel, the model would underestimate the imputed horizon of these forecasts, by underestimating their positive influence owing to their role as proxies of expected growth.

\footnotetext{
${ }^{7}$ While the "discount" or weighting factor $[\rho=\mathrm{P} /(\mathrm{P}+\mathrm{D})]$ used in the model approximation should be somewhat smaller in the early period, due to the higher average dividend yield in the 1980 s, the difference would not be nearly enough to justify the difference in coefficient estimates.
} 


\section{Summary and Implications}

The empirical analysis strongly confirms the value-relevance of analysts' long-term earnings growth forecasts. In particular, most regression coefficient estimates suggest that a 1 percentage point increase in expected earnings growth can explain a 4 to 8 percent boost in an industry's PE ratio. According to the model, these regression coefficients imply that the market treats these forecasts as having an applicable horizon of at least 5 years, and perhaps as many as 10 years. Results from splitting the sample indicates that long-term growth forecasts had larger valuation effects during the past decade than they did in the previous decade, which suggests that the upper-end estimates (the 10-year horizon) may be more relevant for the more recent period. In light of the 4 percentage point increase in the "bottom-up" growth forecast for the S\&P500 during the latter half of the 1990s (documented in figure 1), these findings suggest that the increrase in long-term growth expectations might account for as much as a $32 \%(8 \times 4 \%)$ rise in the market PE ratio over those years, about half of the total increase.

The empirical relation between equity valuations and long-term growth forecasts suggests that investors view such forecasts as strong indicators of growth prospects for several years. It would thus appear that the market places a great deal of faith in the ability of analysts to divine differences in firm or industry long- term prospects; but, this begs the question: How good are such longer-term growth predictions? A detailed analysis of this issue is beyond the scope of my study; however, some recent research suggests that investors could well be misguided in putting so much weight on these forecasts.

One finding is that long-term forecasts are not only upward biased, like forecasts on more specific, shorter-term horizons, but they also appear to be "extreme"; that is to say, the higher a growth forecast is, the more upward biased it tends to be [Dechow and Sloan (1997), Rajan and Servaes (1997)]. In addition, there is mixed support for the view that analysts over-extrapolate from recent observations [De Bondt (1992), La Porta (1996)].

If the weight placed on these forecasts overreaches the ability of analysts (and perhaps anyone else) to predict long-run performance, the forecasts should be contrary indicators of future stock performance. Indeed, these studies find that stock returns for firms with high longterm growth forecasts tend to be substandard. In an analysis of long-term growth forecasts 
issued from 1982-1984, De Bondt (1992) finds a significant inverse relation between expected growth and excess returns over the subsequent 12-18 months. La Porta's (1996) analysis of forecasts issued from 1982-1991 finds subsequent stock returns to be negatively related to beginning-of-period long-term growth forecasts; and both Rajan and Servaes (1997) and Dechow, Hutton and Sloan (1999) find that post-offering performance of IPO stocks is worse for firms with higher long-term growth forecasts.

Finally, Chan, Karceski and Lakonishok (2003) offer some very interesting evidence on the efficacy of long-term growth forecasts. In particular, they compare realized growth to forecasted growth for firms sorted annually into quintile portfolios based on their I/B/E/S longterm growth forecasts. On average over their sixteen year sample, the median growth rate forecast in the top quintile is 22.4 percent, compared to a median of 6 percent in the bottom quintile, a spread of 16-1/2 percentage points. They compare this spread with the spread between the median growth rates actually experienced in subsequent years. Their calculations imply that, from year 2 through 5, the median realized growth rates in the top and bottom quintiles differed by 5-1/2 percentage points, only a third of the average forecasted differential. ${ }^{8}$

On average, my coefficient estimates suggest that industry portfolios are valued as if the market believes that the differential in long-term growth forecasts should be applied to a six- to seven-year horizon. Of course, there are alternative interpretations of my regression estimates. One possibility is that investors (correctly) expect only a third of the differential between growth forecasts to be realized, but that they apply that smaller differential over a much longer horizon. To rationalize this interpretation, though, investors would need to expect the reduced differential to persist for over 20 years. Such beliefs would appear to fly in the face of another finding by Chan, et al. (2001), that there is remarkably little long-term persistence in firm-level income growth. All this would seem to indicate that, even if using the long horizons suggested by my estimates produces more accurate measures of investors' expected returns, using such horizons would seem to be an ill-advised strategy for making portfolio investment decisions.

\footnotetext{
${ }^{8}$ They find that, in the first year after the forecast, median realized growth in operating income for those quintiles was 16 percent and 3-1/2 percent, a spread of $12-1 / 2$ percentage points, about three-fourths of the expected spread. But the spread in median realized growth narrows to 7 points when the performance period is extended to 5 years. Backing out the strong contribution from the first year yields an implied average growth differential in the subsequent four years (years 2-5) of about 5-1/2 percent.
} 
Like the evidence on stock returns and growth forecasts discussed earlier, the analysis by Chan, et al. (2001) is largely focused on the cross-sectional informativeness of growth forecasts. To complete the picture, an important direction for future research would involve focusing on the efficacy of the time-series information in long-term growth forecasts, measured by changes in such forecasts for a given firm or industry. 


\section{References}

Campbell, John Y. and R. Shiller. 1988. "Stock prices, Earnings, and Expected Dividends." Journal of Finance 43 (July): 661-671.

Campbell, John Y. and R. Shiller. 1989. "The Dividend-Price Ratio and Expectations of Future Dividends and Discount Factors." Review of Financial Studies. 1: 195-228.

Chan, Louis K.C., Jason Karceski, and Josef Lakonishok. 2003. "The Level and Persistence of Growth Rates." The Journal of Finance 58 (April): pp.643-684.

Claus, James and Jacob Thomas. 2001. "Equity Premium as Low as Three Percent? Empirical Evidence from Analysts' Earnings Forecasts for Domestic and International Stock markets." Journal of Finance 56 (October): 1629-1665.

De Bondt, Werner F.M. 1992. Earnings Forecasts and Share Price Reversals. Charlottesville, Virginia: The Research Foundation of the Institute of Chartered Financial Analysts (Monograph).

Dechow, Patricia M., Amy P. Hutton, and Richard G. Sloan. 2000. "The Relation between Analysts' Forecasts of Long-term Earnings Growth and Stock Price Performance Following Equity Offerings.” Contemporary Accounting Research 17 (Spring).

Gebhardt, William R., Charles M.C. Lee, and Bhaskaran Swaminathan. 2001 "Toward an Implicit Cost of Capital." Journal of Accounting Research 39 (June): 135-177.

Harris, Robert S. and Felicia C. Marston. 1992. "Estimating Shareholder Risk Premia Using Analysts' Growth Forecasts.” Financial Management 21 (Summer): 63-70.

Harris, Robert S. and Felicia C. Marston. 2001. "The Market Risk Premium: Expectational Estimates Using Analysts' Forecasts.” Mimeo.

Khorana, Ajay, R. Charles Moyer, and Ajay Patel. 1999. "The Ex ante Risk Premium: More Pieces of the Puzzle." Georgia Institute of Technology (working paper).

La Porta, R.. 1996. "Expectations and the Cross-section of Returns." Journal of Finance 51 (December): 1715-1742.

Lee, Charles M.C., James Myers, and Bhaskaran Swaminathan. 1999. "What is the Intrinsic Value of the Dow?" The Journal of Finance 54 (October): 1693-1741.

Nelson, William R.. "The Aggregate Change in Shares and the Level of Stock Prices." Finance and Economic Discussion Series no. 1999-08. Federal Reserve Board (1999). 
Rajan, R., and H. Servaes. 1997. "Analyst Following of Initial Public Offerings.” Journal of Finance 52 (June): 507-529.

Sharpe, Steven A., 2002. "Reexamining stock valuation and inflation: The implications of analysts' earnings forecasts." Review of Economics and Statistics 84 (November): 632649. 


\section{Table 1}

Sample Statistics for Sector Portfolios (top) and Industry Portfolios (bottom)

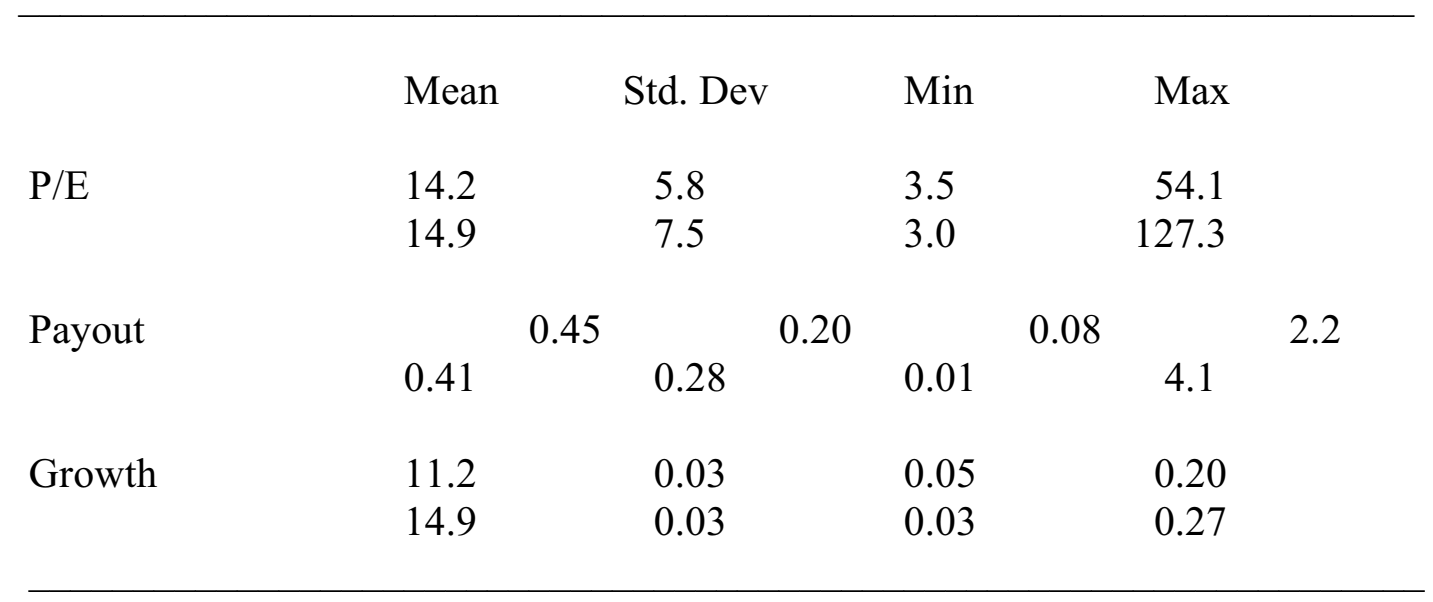

Pearson Correlation Coefficients

\begin{tabular}{lcccc}
\hline & P/E & \multicolumn{3}{c}{ Payout } \\
Payout & & 0.02 & & 1.00 \\
& 0.15 & & 1.00 & \\
Growth & 0.45 & & -0.44 & \\
& 0.30 & & -0.33 \\
\hline
\end{tabular}

The samples runs quarterly from 1983:Q2 to 2001:Q2. In the more aggregated portfolios, there are 801 observations on 11 sectors; the second sample has 4071 observations on 66 industries. 
Table 2

Sector Portfolio Regressions: Dependent variable is the sector-level log PE ratio*

\begin{tabular}{|c|c|c|c|c|c|c|}
\hline & (1) & (2) & (3) & (4) & (5) & $(6)$ \\
\hline Growth $(\beta)$ & $\begin{array}{l}8.05 \\
(0.50)\end{array}$ & $\begin{array}{c}2.00 \\
(0.55)\end{array}$ & $\begin{array}{c}9.69 \\
(1.05)\end{array}$ & $\begin{array}{c}2.66 \\
(0.77)\end{array}$ & $\begin{array}{c}2.30 \\
(0.70)\end{array}$ & $\begin{array}{c}1.69 \\
(0.70)\end{array}$ \\
\hline$\beta /(1-\lambda)$ & & 8.00 & & 7.92 & 6.63 & 5.45 \\
\hline Payout Rate & $\begin{array}{c}0.34 \\
(0.05)\end{array}$ & $\begin{array}{c}0.07 \\
(0.03)\end{array}$ & $\begin{array}{c}0.31 \\
(0.08)\end{array}$ & $\begin{array}{c}0.07 \\
(0.04)\end{array}$ & $\begin{array}{c}0.09 \\
(0.04)\end{array}$ & $\begin{array}{c}0.09 \\
(0.04)\end{array}$ \\
\hline 10-Year Treasury Yield & $\begin{array}{r}-11.99 \\
(0.63)\end{array}$ & $\begin{array}{l}-3.99 \\
(0.78)\end{array}$ & $\begin{array}{l}-11.84 \\
(0.52)\end{array}$ & $\begin{array}{l}-4.73 \\
(0.67)\end{array}$ & $\begin{array}{l}-2.86 \\
(0.57)\end{array}$ & \\
\hline Risk Spread & $\begin{array}{l}-9.90 \\
(4.02)\end{array}$ & $\begin{array}{c}3.41 \\
(1.92)\end{array}$ & $\begin{array}{l}-8.82 \\
(3.27)\end{array}$ & $\begin{array}{c}2.84 \\
(1.78)\end{array}$ & & \\
\hline Expected. Inflation & & & & & $\begin{array}{l}-5.18 \\
(1.04)\end{array}$ & \\
\hline Lagged PE $(\lambda)$ & & $\begin{array}{c}0.75 \\
(0.06)\end{array}$ & & $\begin{array}{c}0.67 \\
(0.05)\end{array}$ & $\begin{array}{c}0.65 \\
(0.05)\end{array}$ & $\begin{array}{c}0.69 \\
(0.06)\end{array}$ \\
\hline Adj. R-Squared & .706 & .910 & .714 & .889 & .893 & .764 \\
\hline Root MSE & .204 & .113 & .172 & .107 & .106 & .085 \\
\hline
\end{tabular}

*801 sector-time observations on 11 sectors over 1983:Q2 to 2001:Q2. Specifications (1) and (2) are estimated with OLS; fixed industry effects are added in (3)-(6) by using OLS on industry mean-adjusted values; year dummies are added in (6). New ey-West robust standard errors are shown in parentheses. Below the standard error for the coefficient on Growth (long-term growth) in (2), (4)-(6) is the implied "long-run" effect of Growth - equal to the coefficient on growth divided by $(1-\lambda)$, where $\lambda$ is the coefficient on the lagged PE. 
Table 3

Industry Portfolio Regressions: Dependent variable is the industry-level log PE ratio*

\begin{tabular}{|c|c|c|c|c|c|c|}
\hline & (1) & $(2)$ & (3) & (4) & (5) & (6) \\
\hline Growth $(\beta)$ & $\begin{array}{l}5.39 \\
(0.37)\end{array}$ & $\begin{array}{c}0.91 \\
(0.16)\end{array}$ & $\begin{array}{c}5.06 \\
(0.36)\end{array}$ & $\begin{array}{c}1.36 \\
(0.21)\end{array}$ & $\begin{array}{c}1.20 \\
(0.20)\end{array}$ & $\begin{array}{l}1.00 \\
(0.22)\end{array}$ \\
\hline$\beta /(1-\lambda)$ & & 5.45 & & 4.53 & 3.96 & 3.88 \\
\hline Payout Rate & $\begin{array}{c}0.15 \\
(0.02)\end{array}$ & $\begin{array}{c}0.04 \\
(0.01)\end{array}$ & $\begin{array}{c}0.20 \\
(0.02)\end{array}$ & $\begin{array}{c}0.07 \\
(0.01)\end{array}$ & $\begin{array}{c}0.08 \\
(0.01)\end{array}$ & $\begin{array}{c}0.07 \\
(0.01)\end{array}$ \\
\hline 10-Year Treasury Yield & $\begin{array}{r}-10.59 \\
(0.54)\end{array}$ & $\begin{array}{l}-2.87 \\
(0.27)\end{array}$ & $\begin{array}{r}-10.33 \\
(0.38)\end{array}$ & $\begin{array}{l}-3.98 \\
(0.28)\end{array}$ & $\begin{array}{l}-2.38 \\
(0.30)\end{array}$ & \\
\hline Risk Spread & $\begin{array}{l}-5.93 \\
(3.33)\end{array}$ & $\begin{array}{c}4.36 \\
(1.30)\end{array}$ & $\begin{array}{l}-6.83 \\
(2.13)\end{array}$ & $\begin{array}{c}2.26 \\
(1.31)\end{array}$ & & \\
\hline Expected Inflation & & & & & $\begin{array}{l}-3.96 \\
(0.67)\end{array}$ & \\
\hline Lagged PE $(\lambda)$ & & $\begin{array}{c}0.83 \\
(0.02)\end{array}$ & & $\begin{array}{c}0.71 \\
(0.02)\end{array}$ & $\begin{array}{c}0.70 \\
(0.02)\end{array}$ & $\begin{array}{c}0.74 \\
(0.03)\end{array}$ \\
\hline Adj. R-Squared & .421 & .857 & .510 & .792 & .794 & .699 \\
\hline Root MSE & .311 & .155 & .226 & .147 & .146 & .12 \\
\hline
\end{tabular}

*4057 industry-time observations on 66 industries over 1983:Q2-2001:Q2 Specifications (1) and (2) are estimated with OLS; fixed industry effects are added to (3)-(6), by using OLS on industry mean-adjusted values; year dummies are added in (6). Newey-West robust standard errors are shown in parentheses. Below the standard error for the coefficient on Growth (long-term growth) in (2), (4)-(6) is the implied "long-run" effect of Growth - equal to the coefficient on growth divided by $(1-\lambda)$, where $\lambda$ is the coefficient on the lagged PE. 
Table 4

\section{Sector Growth Effects in Industry Portfolio Regressions}

Coefficient on:

Industry Growth

Sector Growth

Total
(1)

4.35

1.87

6.22
(4)

3.62

3.40

7.02

Coefficients on growth forecast's are all significant at the 1 percent level. Figures under specifications (4) refer to implied long-run effects of growth, analogous to those in column (4) of tables 2 and 3.

\section{Table 5}

\section{Coefficients on Growth in Early \& Late Samples}

\begin{tabular}{cccc}
\multicolumn{2}{c}{ Sectors } & \multicolumn{2}{c}{ Industries } \\
$(1)$ & $(4)$ & $(1)$ & $(4)$ \\
& & & \\
6.1 & 2.9 & 4.0 & 2.3 \\
10.0 & 10.6 & 6.5 & 4.5
\end{tabular}

Coefficients on growth forecast's are all significant at the 1 percent level. Figures under specifications (4) refer to implied long-run effects of growth, analogous to those in column (4) of tables 2 and 3. 